\title{
Medical Acupuncture: Past, Present, and Future
}

\author{
Richard C. Niemtzow, MD, PhD, MPH
}

\section{THE PAST}

$\mathbf{I}$ CAME ACROSS THREE issues of our early journals-two were under an older name and the third was under the current name. All three issues measured $5 \frac{1}{2} 2^{\prime \prime}$ inches wide and $81 / 2$ " high, and were printed in black and white. The first was The American Academy of Medical Acupuncture Review, Volume 4, Fall/Winter 1992, Number 2. The Editor-inChief was Christina Stemmler (at the time née de la Torre), MD. In this issue, there was a Guest Editorial by Gary Kaplan, DO. He wrote the following:

It is my belief that we are standing on the threshold of change in our medical care system and that it will be as profound as the effect of Cartesian philosophy and the advent of the germ theory. Much has happened since James Reston's postoperative pain was resolved with acupuncture by Li Chang Yuan in 1971. There are approximately 2,000 3,000 physicians and 6,000-9,000 non-physician practicing acupuncture in this country. The National Institutes of Health has been mandated by the U.S. Senate to establish an office to investigate unconventional medical practices. It appears that acupuncture research will finally receive the funding necessary to perform legitimate investigations that will enable acupuncture to take its proper place in the United States medical system. The social and political stage is set for an acupuncture acceptance into mainstream medical practice. $^{1}$

The second issue of The American Academy of Medical Acupuncture Review was Volume 6, Spring/Summer, 1994, Number 1. Dr. Stemmler stated in an Editorial that, after 5 years, with the journal, there was a search for a new Editorin-Chief. ${ }^{2}$

Dr. Stemmler was followed by W. Robert Roalfe, MD, as the next Editor-in-Chief, and then myself sometime around 1995. The third issue was a 1997 issue of Medical Acupuncture (note the name change of the journal), Volume 9 ,
Fall/Winter 1997/1998, Number 2. At that time I was already fully engaged as Editor in-Chief. I wrote in my Editorial:

Acupuncture has become part of mainstream medicine in the United States. In the next few years, I predict that an Americanized version of acupuncture will begin to emerge. Needles will be replaced by electronic contacts over the classical Chinese points. Computers will assist in many treatment configurations. Acupuncture will be integrated into allopathic medical practice. "a l'America" style. How will all of this come about? Who will lead the way? We must begin to communicate through the journal! ${ }^{3}$

\section{THE PRESENT}

Medical Acupuncture is now published every other month and has a high visibility around the globe. It is widely accessed with more than 1000 full-text downloads per month, which is a $91 \%$ increase to the ove the same time last year. The Journal is included in the collections of key libraries and institutions all over the world. We have paid subscribers in 35 countries and provide the journal free online to 106 developing nations via a World Health Organization program called Health InterNetwork Access to Research Initiative (e-mail to Medical Acupuncture authors from me, August 5, 2013).

The journal is now larger in size and prints in black and white with some color. The content is significantly more voluminous. What has not changed is the splendid articles from our talented membership worldwide. We now have an international editorial board that has been very faithful in performing reviews and contributing articles despite their busy schedules. The submission process is online now. The entire process is automated. By gosh, I do not have to ask authors to send me their diskettes any more!

The opinions and assertions contained herein are the private views of the author and are not to be construed as official or as reflecting the views of the United States Air Force Medical Corps, the Air Force at large, or the Department of Defense. The author indicates that he does not have any conflicts of interest. 
I read every article through the review process many times. If an author appears to be having challenges, our dedicated staff and I are more than eager to assist. I receive many e-mails asking me if an article is worth publishing. Articles arrive from foreign countries not necessarily in the "King's English." We try very hard to correct these, but of course, rewriting is not possible. Practically every day, the status of all articles that are being processed are reviewed. It is a never ending process. Of course your Editor writes an Editorial every other month. Since 1995, I have never missed writing one-that is 18 years worth of Editorials! Unfortunately, over the years I have received very few comments on my Editorials. Only the ones in which I wrote about "Spirits" and the like generated e-mails and phone calls for more. I guess we are due for another one soon!

\section{THE FUTURE}

Should I predict the future of the Journal? I see a journal that will have Continuing Medical Education credits. Will we publish every month? That will depend on you. In fact you are the lifeblood of the journal. Without your submissions, Medical Acupuncture would not exist. I encourage all of you new and experienced authors to challenge yourselves to produce a articles. Many people are loath to write, but, actually, it can be a very enjoyable and educational experience. And our staff is ready to jump-in to help you!

Will the journal go totally digital? Some of my favorite journals are now digital and, personally, I feel the lack of holding the publications in my hands. There is something special about the feel of paper, with which one can curl up on a coach and read it, rather than looking at a monitor or tablet; it is a different feel. I hope that the future will see the journal on MEDLINE® and other indexing systems. We have been striving to achieve this, but it is a longer process than we anticipated. We will most likely see more special editions. I envision more guest editorials. There may be more clinical trials appearing.

\section{CONCLUSIONS}

The journal is the Qi of communicating Medical Acupuncture. It is different than the Qi that may be inferred by the Chinese sage Lao $\mathrm{Tzu}^{4}$ :

- "Look, it cannot be seen-it is beyond form." Medical Acupuncture is seen worldwide.

- "Listen, it cannot be heard-it is beyond sound." Medical Acupuncture is the voice of many acupuncturists.

- "Grasp, it cannot be held-it is intangible" Medical Acupuncture is very tangible in our hands!"

- "The Three are indefinable—are one."

\section{REFERENCES}

1. Kaplan G. Guest editorial. Am Acad Med Acupunct Rev. 1994;4(2):1.

2. Stemmler C. Editorial. Am Acad Med Acupunct Rev. 1994; $6(1): 1$.

3. Niemtzow RC. Med Acupunct 1997/98;9(2):5.

4. Poem of Quotes. Look It Cannot Be Seen Poem by Lao Tzu. Online document at: www.poemofquotes.com/laotzu/look-itcannot-be-seen.php Accessed September 9, 2013.

-Richard C. Niemtzow, MD, PhD, MPH

Editor-in-Chief 